\title{
Àrees públiques i militars abandonades a Itàlia: Problemes i oportunitats per a la regeneració urbana i la reorganització territorial*
}

\section{Francesco Gastaldi Federico Camerin}

Università Iuav di Venezia. Dipartimento di Progettazione e pianificazione in ambienti complessi

gastaldi@iuav.it

fcamerin@iuav.it

Recibido: mayo de 2015

Aceptado: marzo de 2016

\section{Resum}

La jurisprudència relativa a l’alienació de béns immobles públics a Itàlia neix a la dècada de 1980 i continua durant la de 1990, en un context de crisi dels recursos públics. A més, en l'àmbit nacional, el patrimoni militar sovint ja no satisfa les necessitats de l'exèrcit, atès que es troba en zones marginals, de manera que ja no pot ser útil per al nou context logístic i estratègic d'un sistema de defensa modern.

Aquest article té la intenció de reconstruir breument la història de la reutilització del patrimoni immobiliari públic italià, descrivint el marc legislatiu heterogeni i complex que recau en el procés de regeneració dels béns, especialment en els que havien estat de l'exèrcit. Es proposa fer una crònica de les dificultats que caracteritzen els programes promoguts per l'Estat italià i els procediments connexos, a partir de l'anàlisi de polítiques i de projectes desenvolupats per part de la UE per reconvertir els military brownfields (antics terrenys militars abandonats).

Paraules clau: alienació; patrimoni immobiliari públic i militar; regeneració urbana; Itàlia

* Aquest article és el resultat de la recerca duta a terme pels dos autors. En aquest context, la introducció i les conclusions han estat desenvolupades pels dos autors. Els apartats 3, 4 i 5 s'atribueixen a Francesco Gastaldi i els apartats 2, 6 i 7 a Federico Camerin. 
Resumen. Áreas públicas y militares abandonadas en Italia: Problemas y oportunidades para la regeneración urbana y la reorganización territorial

La jurisprudencia relativa a la enajenación de bienes inmuebles públicos en Italia nace en la década de 1980 y continúa en la de 1990, en un contexto de crisis de los recursos públicos. Además, en el ámbito nacional, el patrimonio militar a menudo ya no satisface las necesidades actuales del ejército y se encuentra en zonas marginales en el nuevo contexto logístico y estratégico, en comparación con un sistema de defensa moderno.

Este artículo tiene la intención de reconstruir brevemente la historia de la reutilización del patrimonio inmobiliario público italiano, describiendo el marco legislativo heterogéneo y complejo que subyace en el proceso de regeneración de los bienes, especialmente en los que habían sido del ejército. Se propone una reconstrucción de las inercias que caracterizan a los programas promovidos por el Estado italiano y los procedimientos conexos, a partir del análisis de políticas y proyectos desarrollados por parte de la UE para la reconversión de los military brownfields (antiguos terrenos militares abandonados).

Palabras clave: enajenación; patrimonio inmobiliario público y militar; regeneración urbana; Italia

Résumé. Surfaces publiques et militaires abandonnées en Italie : problèmes et opportunités pour la régénération urbaine et la réorganisation territoriale

La réglementation relative à la vente du patrimoine immobilier public est mise en place dans les années quatre-vingt-cinq et se poursuit dans les années quatre-vingt-dix, dans une situation de crise des ressources publiques. En Italie, dans de nombreux cas, le patrimoine militaire ne répond plus aux actuelles exigences de l'armée. Il est en outre souvent situé dans des zones devenues marginales compte tenu des changements survenus dans le contexte logistique international, et obsolète par rapport aux systèmes de défense modernes.

Cet article a pour but de reconstruire les étapes de la réutilisation du patrimoine immobilier public italien en brossant le tableau législatif hétérogène et complexe sur lequel se fonde le processus de réutilisation des biens, en particulier les anciens biens militaires. Nous proposons une reconstruction des difficultés et des opportunités pour la requalification urbaine des villes italiennes, les programmes promus par l'État italien, en nous référant également à l'analyse de politiques et de projets soutenus par l'UE pour la reconversion des friches militaires (military brownfields).

Mots-clés: vente; patrimoine immobilier public et militaire; régéneration urbaine; Italie

Abstract. Abandoned public and military sites in Italy: Challenges and opportunities for urban regeneration and territorial reorganisation

Legislation concerning public real estate "spin offs" in Italy dates from the 1980s and continued until the 1990s in the midst of a public resource crisis. In many cases, the military real estate of Italy no longer responds to the current needs of the army and is often located in areas that have become marginal over time due to the changing international strategic and logistic context, as well as being dated compared to more modern defence systems.

This article aims to explain the history of the redevelopment of Italian public real estate by exploring the heterogeneous and complex legislative framework which underlies the property reuse process, especially former military properties. The difficulties characterizing the programs promoted by the Italian government are described based on an analysis of EU policies and projects for the reconversion of military brownfields.

Keywords: property disposal; public and military real estate; urban regeneration; Italy 


\section{Sumari}

1. Introducció

2. Programes i projectes europeus de cooperació transnacional per a la reconversió del patrimoni militar abandonat

3. Problemes i debats sobre la conversió dels edificis públics i militars a Itàlia 4. Una entitat especial per gestionar el patrimoni públic italià: l’Agenzia del Demanio
5. Els nous buits urbans: les àrees militars abandonades

6. Un marc legislatiu heterogeni, variable i fragmentat

7. Els nous acords per reconvertir les zones militars abandonades a Itàlia

8. Conclusions

Referències bibliogràfiques

\section{Introducció}

En el context de crisi que actualment sacseja el sistema capitalista, amb un greu dèficit pressupostari dels estats del món occidental, ha tornat a sorgir el tema de l'alienació i reutilització de béns públics, sobretot militars, per eixugar el deute públic. Aquesta situació és comparable al fenomen de la desamortització del segle XIX, en què els governs liberals europeus promovien la venda de béns i finques, tant del clergat com d'institucions civils (Villani, 1964; Silveira, 1991; Rueda, 1998; Bodinier et al., 2009). A més de les conseqüències socials, econòmiques, culturals, polítiques i ideològiques que va comportar aquesta operació, també va contribuir a modernitzar les ciutats, amb construccions de més altura, eixamples i espais públics nous gràcies als enderrocaments. Els antics immobles eclesiàstics van passar a tenir uns altres usos: molts es van transformar en edificis públics (museus, casernes, hospitals), uns altres van ser enderrocats per obrir carrers nous o eixamplar-ne els existents i uns altres es van convertir en temples parroquials o es van subhastar i van passar a mans privades.

El patrimoni ferroviari és un altre tipus de propietat pública que sovint s'ha privatitzat després de l'abandó sofert pels efectes de la desindustrialització i per la crisi dels trànsits ferroviaris enfront dels nous mitjans de transport, en particular el trànsit per carretera i també, en segon terme, aeri. Igual que els béns immobles públics, els traçats del ferrocarril en desús constitueixen una oportunitat excepcional i única per promoure la transformació urbana i el desenvolupament d'una idea de ciutat: l'extensió d'aquestes zones, la seva ubicació i l'alt grau d'accessibilitat del transport públic és crucial en les qüestions de regeneració urbana (Montedoro, 2011). A més, s'ha de tenir en compte l'oportunitat implícita de remodelar la geografia de les ciutats amb referència als espais que hi ha al voltant de les línies ferroviàries abandonades i l'establiment de noves jerarquies urbanes. Per això, en el context europeu i internacional, es van desenvolupar diferents projectes de reconversió per a les estacions abandonades a les ciutats (Bertolini i Spit, 1998) i també per als traçats de 
tren, molt sovint amb la finalitat de crear-hi vies verdes (Aycart Luengo, 2001; Rovelli et al., 2004; Conlin i Bird, 2014).

A més d'aquests dos tipus de béns, en el context de modernització i retallades dels exèrcits europeus i americans que van tenir lloc al llarg de la darrera part del segle Xx, es van abandonar moltes àrees militars a les ciutats. En el marc d'una evolució global del sistema de seguretat en relació amb els canvis de la situació internacional des del final de la Guerra Freda i els atemptats de l'11 de setembre de 2001, els països de la UE (als quals, des de 2007, també s'hi van unir els de l'Europa oriental) i els Estats Units (Warf, 1997) van iniciar un procés de reestructuració dels propis sistemes de defensa. Tot això d'acord amb les directrius de les principals organitzacions internacionals per a la pau i la seguretat mundial i també seguint les línies guies del document $A$ secure Europe in a better world (European Union, 2003), aprovat per l'alt representant de la UE Javier Solana. En el cas de països com ara Alemanya, França i Anglaterra (Servizio Studi del Senato, 2009), la modernització té com a objectiu principal millorar l'eficiència, la flexibilitat i la professionalitat de l'organització militar de guerra, però, en aquest context, es necessita una gestió del patrimoni immobiliari de la defensa més racional i menys costosa, tant pel que fa als béns estratègics com per a les àrees abandonades i destinades a l'alienació. Als Estats Units, segons les dades de Stephen Harness (2014), el programa BRAC (Base Realignment and Closure) ha comportat el tancament de 350 instal.lacions militars entre 1988 i 2005.

Encara que alguns països europeus han promogut, de manera progressiva i reeixida, uns processos de reconversió dels antics béns militars (a través de programes tant de matriu estatal, per exemple, la Mission pour la réalisation des actifs immobiliers a França, com en termes de cooperació europea, com ara el projecte KONVER), en el cas italià s'ha produït una situació general que es caracteritza per una alta incertesa i per la discontinuïtat en la fase d'implantació i realització de les polítiques d'alienació i reutilització.

En la literatura internacional, l'atenció s'ha centrat en les polítiques de regeneració urbana dels anomenats brownfields (Marcuse i Van Kempen, 2000) derivats del procés de desindustrialització (Dixon, 2006; Vojvodíková, 2010). Aparentment, $s$ 'ha atorgat menys interès a les antigues zones militars, generades pels processos d'abandó posterior a l'any 1989 (Matlovič et al., 2001). Durant els últims quinze anys, especialment als països postcomunistes, diversos autors s'han interessat pels military brownfields (Simion-Melinte, 2012; Hercik et al., 2014), principalment des del punt de vista de la descontaminació dels sòls i la requalificació general i sostenible del territori (Reimer, 1997; Nijkamp et al., 2002; Ferber et al., 2006; Thornton, 2007; Wedding i Crawford-Brown, 2007; European Court of Auditors, 2012), la qual cosa va incloure aspectes del desenvolupament econòmic i social (Holman, 2001; Jauhiainen, 2002; Bagaeen, 2006), de vegades amb enfocaments participatius (Doak, 1999; Hill, 2000; Van Driesche i Lane, 2002; Perić i Furundžić, 2013). A més d'aquestes qüestions, s'hi van tractar aspectes relatius a les ciutats fortificades, les normatives, el finançament, l'avaluació de riscos i el turisme al llarg de diverses conferències 
internacionals, com ara durant els esdeveniments biennals de Defence Sites, que van començar el 2012 i seguiran el 2016 (Brebbia i Klark, 2012 i 2014).

Un cop definit el context en què s'insereix el treball, la metodologia que seguirem serà la següent: a partir de la minsa quantitat d'estudis realitzats a Itàlia en referència a la reconversió del patrimoni públic en desús, s'hi desenvolupa una reflexió sobre les qüestions emergents per a la reutilització de les zones militars abandonades en una perspectiva general de transformació de les ciutats italianes, com una oportunitat per restituir al territori de pertinença àrees amb localització sovint cèntrica i estratègica des d'una òptica de regeneració urbana. Per alimentar el debat sobre aquesta temàtica, s'hi descriu l'estat de la qüestió, fent una anàlisi de les característiques de les àrees militars abandonades, dels programes i dels projectes europeus de cooperació transnacional de conversió, del rol de l'entitat pública italiana que gestiona el patrimoni públic i del marc legislatiu en què s'insereix aquesta qüestió. Finalment, s'hi detalla l'estat actual d'un procediment particular de reutilització de les àrees militars, els anomenats protocolli d'intesa, en algunes de les ciutats italianes principals.

\section{Programes i projectes europeus de cooperació transnacional per a la reconversió del patrimoni militar abandonat}

Des dels anys noranta, la Unió Europea ha començat a estudiar la qüestió de la conversió del patrimoni militar amb el finançament de programes especials elaborats com a components específics de les polítiques estructurals. En l'àmbit europeu, Ponzini i Vani (2012) descriuen la configuració de les intervencions realitzades per desenvolupar els processos de reducció de la presència militar i el pes socioeconòmic que presenten en relació amb el territori.

L'estudi comença a partir de programes com ara Perifra I i II, d'abast més limitat que els KONVER I i II. Els finançaments per als KONVER, definits per cada estat membre sobre la base de les instruccions emeses per la Comissió Europea, han tractat de manera conjunta tant les polítiques laborals i les polítiques d'innovació tecnològica de les petites i mitjanes empreses, com l'aportació a les infraestructures bàsiques en contextos no només urbans, sinó també rurals i suburbans. En relació amb la temporada dels Perifra, aquestes iniciatives han millorat els procediments de despeses i el control financer per part dels diferents actors $i$, sobretot, han establert requisits de les autoritats nacionals de gestió que s'han vinculat a una quota de cofinançament. Sobre aquesta base, hi ha hagut una sèrie de projectes finançats en el marc de KONVER I (especialment en els estudis de viabilitat pel que fa a les conversions de les antigues estructures militars) que s'han beneficiat d'un finançament posterior per al programa KONVER II. La implementació d'aquest tipus de programes en diversos estats europeus no ha estat uniforme ni coherent amb els objectius que es pretenien assolir, atès que van sorgir problemes de caràcter metodològic $\mathrm{i}$ interpretatiu, determinats principalment per les definicions distintes i no comparables entre les estructures militars dels diferents territoris, així com entre les pròpies organitzacions nacionals del sistema de defensa. Tot i les limitacions, 
la programació europea destinada a la reconversió de les herències militars va preveure un cofinançament per un import aproximat de 740 milions d'euros entre 1993 i 1999, la qual cosa va contribuir a crear un marc i un llenguatge comuns i, a partir d'aquesta etapa, a Europa, es va iniciar un diàleg entre actors institucionals i socials amb una cultura administrativa i uns interessos diferents.

Més tard, com que es van deixar de promoure programes i fons especials, la reconversió de les antigues zones militars va ser indirectament suportada amb uns altres plans (com ara els RECITE), de vegades gràcies a la connexió en xarxa de ciutats que s'havien unit per oferir solucions als problemes comuns, per exemple: RE.PAIR (Realising the Potential of Abandoned Military Sites as an Integral part of Sustainable Urban Community Regeneration). Aquest enfocament ha substituït les iniciatives anteriors, i els projectes relatius als patrimonis militars abandonats es van inserir en programes de cooperació transnacionals més genèrics (com ara, per exemple, els Interreg IIIB Cadses i els Interreg IIIC North-East-South-West, una sèrie de projectes dels programes Central Europe i South East Europe). A vegades, la qüestió dels militaries brownfield s'ha associat també a la més coneguda metodologia per reconvertir les àrees industrials MISTER (Military and Industrial SiTEs Reuse), amb l'objectiu de facilitar l'intercanvi d'experiències i de coneixements entre les ciutats $\mathrm{i}$ les regions europees, implementant d'aquesta manera bones pràctiques i models de gestió, per tal de colllocar la conversió militar al centre dels processos de regeneració urbana, seguint diferents prioritats (incloent-hi la sostenibilitat ambiental i econòmica, el turisme sostenible, etc.).

Bàsicament, el tema de la reconversió del patrimoni militar abandonat s'ha plantejat com un problema estructural i econòmic connectat a la disminució de la presència de l'exèrcit, i no principalment com un assumpte de desenvolupament territorial. En una situació de crisi estructural persistent del sector immobiliari, l'enfocament europeu (que recentment comprèn també l'Europa de l'Est) sobre la regeneració urbana dóna poca importància a la reutilització de les antigues zones militars. A tot això, cal afegir-hi la importància sobre la disponibilitat dels ministeris de Defensa dels estats membres de reconèixer formalment la pèrdua de l'interès públic per la defensa militar en un edifici o en una àrea. El debat internacional segueix sent feble, amb pocs experiments a escala urbana capaços de connectar-se a la reutilització del patrimoni dels exèrcits per reduir les desigualtats socials i territorials i limitar l'impacte sobre el medi ambient, així com garantir el desenvolupament econòmic i cultural de les zones urbanes, oferint serveis de qualitat $\mathrm{i}$ altres recursos.

\section{Problemes i debats sobre la conversió dels edificis públics i militars a Itàlia}

Només recentment a Itàlia està madurant una sensibilitat cap als artefactes arquitectònics produïts entre els segles XIX i XX. A aquest període, hi pertanyen molts edificis militars i públics de considerable valor arquitectònic, paisatgístic, simbòlic i identitari, testimoniatge de les memòries individuals i col-lectives. 
Es tracta d'una herència molt significativa que es va formar a partir de la unificació d'Itàlia incorporant edificis religiosos i monàstics, que va ser seguit per la creació d'artefactes finalitzant l'organització de la nova estructura de l'Estat. Els edificis de l'Administració estatal són construccions on s'han realitzat amb més evidència les transformacions tecnològica i organitzativa, per exemple, per a la introducció d'estructures de formigó armat. A més, presenten estils arquitectònics sovint innovadors i que caracteritzen els diferents períodes (gràcies als dissenyadors i als enginyers molt preparats tècnicament i culturalment). En el cas de les antigues àrees militars, es van construir preferentment entre els anys seixanta del segle XIX i els anys trenta del segle xx segons els models codificats $i$ repetits en diferents contextos locals. Les accions haurien de combinar viabilitat econòmica, recuperació i reinterpretació virtuosa d'aquests béns, amb la finalitat de redefinir l'estructura i l'organització de parts dels sistemes urbans o territorials.

La immobilitat que caracteritza el tema dels béns públics contrasta molt amb la velocitat extrema amb què el món polític ha canviat $i$ ha superposat moltes lleis. S'han anat acumulant les regles sense abordar la veritable qüestió de fons que hauria de constituir la base de totes les estratègies i de tots els programes polítics, és a dir, el coneixement i les relacions amb el territori al qual pertanyen els béns. Els processos d'alienació dels immobles públics (sovint, grans edificis situats en zones ja equipades amb infraestructures $\mathrm{i}$ amb grans extensions d'espai obert) exerceixen un impacte significatiu sobre moltes qüestions que afecten les decisions de les autoritats locals. Per la reutilització dels béns, es requereix que les ciutats, fins i tot les de superfície mitjana o petita, elaborin unes accions polítiques i administratives complexes, tant en referència a les estratègies urbanes relatives a l'estructura del territori i als escenaris de futur desenvolupament econòmic, com en els procediments i en les eines més adequades per la col-laboració entre els diferents actors i la creació de valor afegit en el mercat immobiliari.

L'Institut Bruno Leoni (2011) ha estimat que el valor dels immobles i dels habitatges públics (de l'Estat, de les autoritats locals, de les regions) és de 450 mil milions d'euros, malgrat que un estudi inicial de l'agència que gestiona el patrimoni públic a Itàlia, l'Agenzia del Demanio (Magistà, 2007), encara no ha arribat a fer una revisió completa i fiable de l'estoc referent a les propietats públiques capaç d'assumir els veritables valors dels edificis. Avui en dia, gairebé sempre s'atribueixen valors d'inventari i no reals, i la conseqüència lògica d'aquesta assignació incorrecta és la venda rebaixada, especialment d'aquells béns situats a les parts centrals i estratègiques de la ciutat, per la imatge d'alt valor de renda que ofereix als compradors.

Cal destacar que la decisió de disposar d'un bé públic no pot deixar-se exclusivament en mans de consideracions econòmiques, perquè qualsevol hipòtesi de venda ha de passar primer per una acurada ponderació de l'existència d'un interès general per la preservació del bé (per assignar-ho a la mateixa Administració pública o, més en conjunt, a la comunitat). Això requereix un alt nivell de consciència sobre les necessitats econòmiques i socials del territori, 
per la qual cosa la cessió ha de ser una espècie d'últim recurs, la raó última que quedarà després de considerar totes les altres alternatives. En relació amb el passat, s'ha enfortit la consciència que, si s'administren correctament, els béns públics constitueixen, per a l'Estat i per a les autoritats locals, no només una font de despeses, sinó també una possible entrada de riquesa.

A vegades, per economitzar, no és necessari vendre. N'hi hauria prou de reconvertir les antigues casernes perquè realitzessin unes altres funcions públiques sense haver de pagar lloguers o consumir més sòl. Els amplis espais alliberats pels militars es podrien convertir en presons o en edificis per als cossos de policia, per als bombers o per als tribunals, però, sovint, les diverses institucions de l'Estat estan en desacord entre elles i no estableixen un diàleg de col-laboració sobre l'avaluació de tots els problemes ni sobre les possibles solucions que hi pugui haver.

L'experiència ha demostrat que una gestió exclusivament pública dels béns comuns no necessàriament n'assegura un ús d'acord amb un bon funcionament, mentre que una possible transició de la propietat del bé, que fins i tot en podria proporcionar un ús econòmic millor, no implica necessàriament una renúncia a la funció que desenvolupa, que encara pot ser preservada i garantida a través d'instruments jurídics adequats.

\section{Una entitat especial per gestionar el patrimoni públic italià: l'Agenzia del Demanio}

L'Agenzia del Demanio italiana —en català, Agència del Domini- es va crear l'any 1999 com a resultat de la nova organització del Ministeri d'Economia i Finances en quatre òrgans diferents (Ingressos, Territori, Duanes i Béns de Domini Públic). L'Agència ha rebut un fort impuls per gestionar el patrimoni immobiliari públic de manera eficaç i eficient, se li ha atorgat un nou estatut amb una autonomia financera i de gestió més àmplia que les altres agències estatals i la seva comesa depèn de la supervisió i el finançament del Ministeri d'Economia (Corte dei Conti, 2014).

Durant la primera dècada del segle XxI, l'Agència es va convertir en una empresa pública i va canviar radicalment la seva composició. A partir de 2012, va ser promogut un nou model organitzatiu sota el qual l'entitat s'organitzava en estructures centrals - amb activitats de control, de gestió i d'administració- $\mathrm{i}$ en estructures territorials regionals i interregionals, respectivament 12 i 4, que operaven sobre el patrimoni relatiu al propi àmbit de referència.

Entre desembre de 2003 i octubre de 2007, es va concloure el primer cens de la propietat estatal $i$, avui en dia, l'Agència gestiona un patrimoni immobiliari que inclou aproximadament 47.000 unitats consistents en edificis i terrenys, també del conjunt historicoartístic.

Entre les activitats de gestió del patrimoni estatal, cal assenyalar que, al llarg de l'any 2013, el valor total de la venda d'actius immobiliaris va pujar 371,2 milions d'euros, dels quals 320 provenien de la venda extraordinària d'un conjunt de 34 edificis governamentals a la companyia estatal especialitzada en el 
desenvolupament del patrimoni immobiliari públic, la societat Cassa Depositi e Prestiti Investimenti Sgr.

En el procés del federalismo demaniale — publicat al Decret Llei 85/2010 en relació amb el fenomen de devolució, accessori per al federalisme fiscal, que és la transferència a títol gratuït a les autoritats locals de béns de propietat de l'Estat (Antoniol, 2010; Lo Conte, 2011)_, a més del procediment simplificat per transferir béns de propietat estatal a les administracions locals en virtut de l'article 56 del Decret Llei 69/2013, es va continuar treballant en relació amb l'article 5.5 del Decret Legislatiu 85/2010 sobre l'assignació als governs locals de la propietat dels béns pertanyents al conjunt historicoartístic.

De 2010 a 2015, els governs locals van reclamar 630 béns. El procediment va ser completat per a prop de 400 propietats, mentre que, per a més de 200, la petició va ser denegada o es va considerar caducada. Encara és elevat el nombre d'iniciatives paralitzades després de la presentació de la sol-licitud, és a dir, sense la preparació d'un programa per a la valorització del bé per part de l'Administració demandant. Entre les novetats del 2015, l'Agència ha desenvolupat una nova oportunitat per promoure nous processos de reutilització dels béns immobles pertanyents a regions, províncies i municipis amb el programa Proposta immobles 2015.

A més a més, cada any, mitjançant la Llei de pressupostos, el Govern italià sempre encarrega a l'Agència tasques noves, encara que el Ministeri d'Economia i Finances hagi disminuït cada vegada més els fons assignats.

Es presta poca atenció al fet que - a causa d'un nou disseny de la funció i de la composició general de l'entitat, principalment pel que respecta al seu nivell central-, encara se sap molt poc de la capacitat operativa real de les sucursals que hi ha al territori, ja que encara estan subjectes al procés de reorganització de l'Agència. Les poques investigacions realitzades sembla que donen suport a la tesi que, en relació amb una suposada "homogeneïtat» en referència a la capacitat d'actuació al territori, les estructures demanials disposen de nivells de competència variables i són distribuïdes per l'Estat de manera poc uniforme.

\section{Els nous buits urbans: les àrees militars abandonades}

En el context de modernització i de retallades dins dels exèrcits europeus i americans ${ }^{1}$, fins $\mathrm{i}$ tot les forces armades italianes s'han adaptat a les alteracions respecte a les necessitats estratègiques: l'Exèrcit ha passat de tenir 300.000 efectius a tenir-ne 110.000; l'aeronàutica, des de l'any 2000 fins avui, ha venut quinze aeroports als civils (Ciampino, el segon aeroport de Roma, des de 2013, és formalment civil) i el 2001 es va abolir el servei militar obligatori. De l'expansió de l'Exèrcit i el seu desplegament a l'est d'Itàlia (en particular, la regió de Friuli Venezia Giulia era la frontera que n’havia estat més important),

1. S'estima que, en l'última dècada del segle $\mathrm{xx}$, al món s'han convertit a ús civil al voltant de vuit mil àrees militars, que corresponen a una extensió de gairebé un milió d'hectàrees, de les quals 386.000 solament són a Alemanya (Bonn International Center for Conversion, 1997). 
ha començat un canvi lent cap a una concentració militar en pocs llocs, més sostenibles, tant des del punt de vista econòmic com ambiental.

A Itàlia, el tema general de l'alienació del patrimoni immobiliari públic és part del debat polític i administratiu des de fa molts anys, però ha estat principalment enfocat a qüestions de comptabilitat i com una possible manera de reduir el deute públic (IBL, 2011), i s'han desplaçat a un segon lloc uns altres aspectes lligats a l'urbanisme, la gestió de les ciutats, els processos de desenvolupament cultural i la promoció del territori. En els estudis urbans italians, excloent-ne els treballs de Davide Ponzini i Marco Vani (Ponzini, 2008; Ponzini i Vani, 2012) i de la Societat Italiana d'Urbanistes (Gaeta i Savoldi, 2013), no existeix cap reflexió seriosa ni completa sobre el paper que podria exercir la reutilització dels béns públics, sobretot militars (Baccichet, 2015), com una ocasió per desenvolupar o acompanyar el desenvolupament de regeneració urbana i de planejament territorial, com una oportunitat per reconfigurar les àrees centrals d'alt valor simbòlic o per reduir els processos de consum del sòl. En termes d'anàlisi de polítiques públiques, tampoc no hi ha cap reflexió sobre les dificultats a les quals s'han enfrontat les administracions locals en la configuració de processos virtuosos de reutilització dels immobles oficials.

Les antigues zones militars constitueixen una herència vasta, complexa $\mathrm{i}$ geogràficament dispersa, abandonada o sovint sobreutilitzada. Encara no existeix, però, cap cens complet per part del Ministeri de Defensa dels béns militars en ús i en desús a Itàlia distribuït per províncies i per regions. Entre les característiques d'aquest patrimoni, se'n reconeix l'obsolescència de les instal-lacions, l'escassa integració amb el territori on s'ubiquen, la degradació i els riscos ambientals potencials derivats de la presència d'amiant i de sòls contaminats. Els costos del sanejament de les àrees afecten decisivament l'èxit d'una operació, de manera que, en alguns casos, l'avaluació incorrecta (generalment subestimada) i les dificultats tècniques d'aplicació poden donar lloc a grans ampliacions dels terminis d'execució del projecte o fins i tot a l'abandó de la iniciativa.

Aquesta tipologia de buit urbà està estretament connectada amb la de les zones industrials abandonades. Si, d'una banda, la reutilització d'antigues zones industrials ha estat un important motor de canvi en el marc de la planificació ciutadana que es va iniciar en les últimes dècades, de l'altra, no existeix avui cap reflexió adequada sobre les dificultats que els governs locals tenen per construir processos viables de la recuperació dels immobles públics, especialment els que eren militars.

Avui en dia, quant de temps es necessita per reconvertir les infraestructures militars que en gran part estan abandonades? Quins usos nous poden fer possible una reconversió de les àrees? Quins tipus de problemes s'han detectat per definir les noves funcions de les zones militars desocupades? Si, en principi, la decisió de construir instal-lacions militars ha obeït a una política potser no expressada de manera explícita, avui el fenomen de restitució dels llocs abandonats no és el resultat d'una estratègia i es mou en un marc completament improvisat. A més a més, la crisi econòmica fa que sigui encara més difícil plantejar la reutilització de grans estructures que, sovint, es troben en àrees periferiques. 


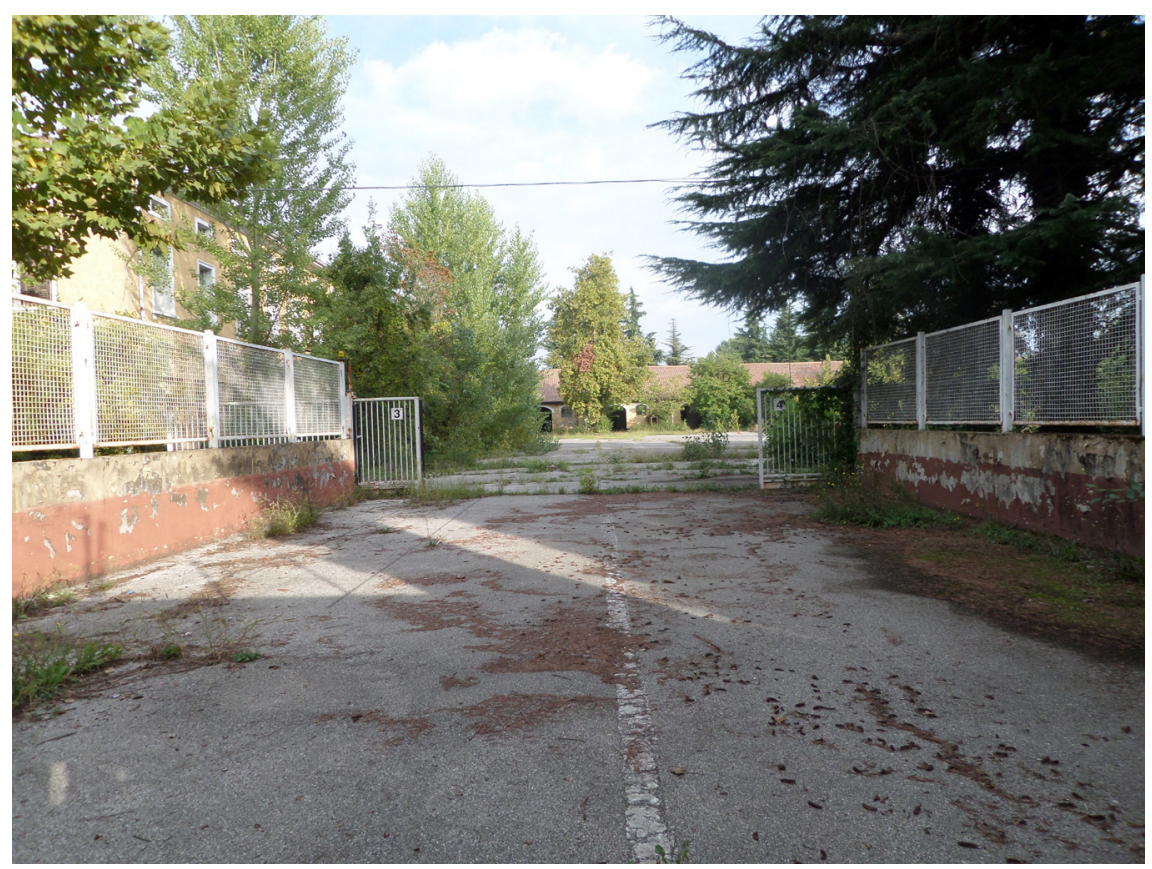

Figura 1. Estat d'abandó de la caserna Salsa a Treviso.

Font: fotografia feta per Federico Camerin (juliol de 2015).

Com a conseqüència, preval la circumstància que les administracions locals italianes no poden utilitzar els béns públics abandonats, sobretot els militars, per regenerar i desenvolupar els espais urbans. Arran d'això, sorgeixen tot d'impactes negatius a causa de les oportunitats perdudes. El canvi constant d'objectius i d'eines introduïts per la normativa de l'Estat han convertit el tema en quelcom tan complex que, en la majoria dels casos, els governs locals no han estat capaços de controlar el projecte de reutilització, la qual cosa ha generat il.lusions i frustracions entre els actors socials i econòmics i ha causat un estat perpetu d'incertesa.

Entre 2014 i 2015 , es van produir accions de protesta per part de la població resident i les associacions contra l'estat d'abandó del patrimoni militar (casernes Tommaso Salsa, en la figura 1, i Silvio Serena a Treviso). Però no només això: les antigues estructures de l'exèrcit han estat ocupades de manera il.legal i es van promovent manifestacions públiques per estimular un debat que insereixi els actors socials i els ciutadans en les decisions unilaterals de les institucions (caserna La Marmora a Torí i caserna Piave a Treviso). Aquestes situacions es produeixen, sobretot, per donar resposta a les operacions de desenvolupament immobiliari en una època de crisi del real estate (caserna Guido Reni a Roma); per defensar els valors historicoculturals 


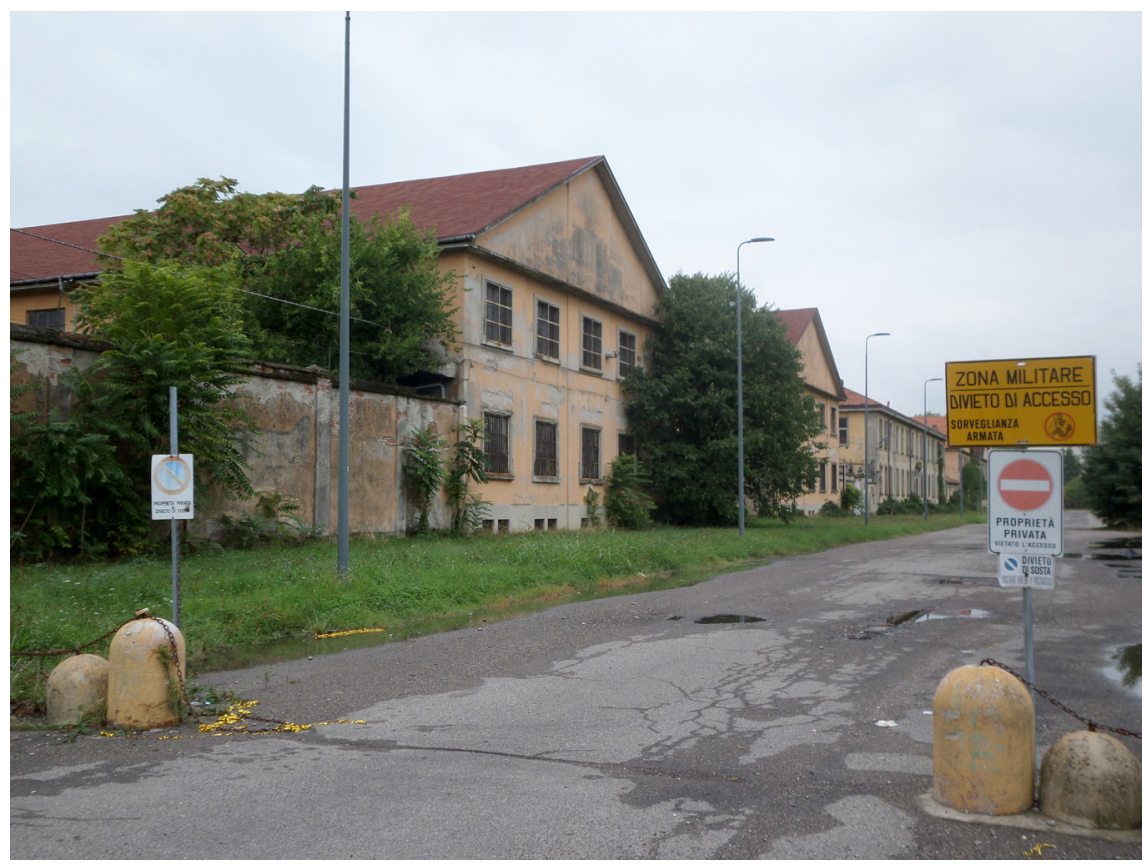

Figura 2. La zona exterior dels magatzems militars Baggio a Milà.

Font: fotografia feta per Federico Camerin (setembre de 2015).

i ambientals de béns protegits (Plaça d'Armes, magatzems militars Baggio i caserna Mameli a Milà, a la figura 2); per promoure idees i projectes de reconversió (Caserna Gavoglio a Gènova), sobretot en referència a habitatges d'emergència social (Caserna Gonzaga a Florència), i, darrerament, també per habilitar espais a les antigues estructures del nord-est d'Itàlia (a les províncies d'Udine i Pàdua), a fi de fer front a l'acollida urgent dels refugiats provinents del nord d'Àfrica.

\section{Un marc legislatiu heterogeni, variable i fragmentat}

Les dificultats per poder reutilitzar el patrimoni públic immobiliari han exercit un impacte negatiu a les ciutats italianes, tant en termes d'habitabilitat als espais urbans en qüestió com perquè obstaculitzen els possibles projectes de reconstrucció que podrien desencadenar processos de desenvolupament $\mathrm{i}$ regeneració. Casernes i edificis públics van ser, en general, els llocs de negoci que fomentaven l'economia local, sovint gràcies a les transferències del Govern central. El tancament o la reubicació que se n'ha fet ha produït efectes negatius sobre l'ocupació, ja que gairebé mai han estat substituïts per altres activitats que poguessin proporcionar ingressos. 
Les polítiques d'alienació donen noves responsabilitats als actors públics implicats, sobre una pluralitat d'interessos, en relació amb la millor utilització dels béns i tenint en compte les seves característiques i el context d'ubicació.

Després de 1999, any en el qual es va instituir l'Agenzia del Demanio, es va promoure un procediment diferent respecte a les polítiques dels anys noranta. Aquest procediment va posar en primer lloc el canvi de destinació d'ús, que havia d'anar seguit de l'alienació. Es van crear projectes molt ambiciosos que van esdevenir pràcticament ineficaços $i$ que van aconseguir resultats ben modestos. Entre els diversos esdeveniments de la primera dècada del segle XXI, s'hi poden incloure les operacions de titulacions, respectivament anomenades SCIP 1 i SCIP 2 -operacions promogudes pel Decret Llei 351/2001 i realitzades respectivament al desembre de $2001 \mathrm{i}$ al desembre de 2002-i el PUVaT (Programma Unitario di Valorizzazione Territoriale), introduït per la Llei de Finances de 2007. La hipòtesi bàsica va predir que, una vegada constituïda una massa crítica suficient d'immobles i després d'haver compartit una mateixa perspectiva d'intervenció urbana, els diversos PUVaT podrien representar l'element desencadenant d'una iniciativa privada per finançar la conversió dels edificis i que l'Estat garantís el pagament del cànon d'arrendament —el federalismo demaniale i el Pla municipal d'alienacions i valoritzacions immobiliàries - que consta a l'article 58 del Decret Llei 112/2008 i que ha facilitat que les autoritats locals gaudeixin d'una manera facil i ràpida de sanejar les finances amb la venda dels seus immobles.

En una situació de problemes continus per a les finances de l'Estat, a partir de 2011, es va produir una nova i intensa activitat legislativa sobre el patrimoni públic immobiliari —els decrets «Salva Itàlia», «Mil pròrrogues», "Simplifica Itàlia», "Desenvolupa Itàlia», "Revisió de despeses públiques»; el Decret Llei 83/2012, que institueix el «Pla Ciutat», i el Decret Llei 87/2012_, que ha convertit lentament en obligació l'operació del canvi d'ús dels immobles públics. Aquesta nova línia podria constituir una oportunitat de regeneració per a molts entorns urbans, però no s'ha deixat de plantejar la qüestió sobretot amb un enfocament financer.

Aquest marc normatiu heterogeni, variable i fragmentat va crear, al llarg del temps, una superposició de rols i de responsabilitats entre les diferents administracions institucionals estatals i locals. A partir dels anys noranta, s'observa una forta limitació dels governs locals per plantejar l'ordenació i la gestió del territori sobre les àrees públiques i militars abandonades, és a dir, es nota la dificultat que pateixen les administracions locals de proposar els possibles nous usos dels espais abandonats en un futur escenari de desenvolupament urbà. Sovint, els municipis, a més de no tenir recursos econòmics, tampoc disposen de recursos humans, i quan en tenen, els manca el coneixement necessari per treballar amb un tipus de procediment tan complex. L'absència d'estratègies clares de desenvolupament territorial fixades dins d'un document programàtic $i$ un escenari socioeconòmic ben definit contribueix a obstaculitzar la iniciativa empresarial i la interacció entre els diferents grups d'interès. A més, la tendència purament especulativa i oportunista de molts 
operadors immobiliaris, la ineptitud per proposar idees innovadores i la mancança d'una veritable anàlisi sobre la demanda de béns condueixen al fracàs de l'operació. Com a demostració de les afirmacions precedents, enfront de la gran participació de les autoritats territorials i locals en el plantejament de diverses idees per implementar els diferents programes al llarg del temps, s'han observat moltes mancances del sistema d'alienació i reconversió dels béns públics abandonats. En primer lloc, s'ha detectat la falta de finançament necessari per executar els processos i, en segon lloc, la lentitud dels procediments burocràtics, sobretot pel que respecta a l'adjudicació de les licitacions públiques i a l'aprovació dels processos de planejament urbanístic (Parlato i Vaciago, 2002; Vaciago, 2007).

Entre 2013 i 2014, a més de diversos programes de vendes impulsats per l'Estat amb l'objectiu d'alienar al territori italià béns per valor de mil milions d'euros els anys 2015 i 2016, i 600 milions el 2017, s'han fomentat tres processos. Primer, s'ha reprès l'anomenat federalismo demaniale mitjançant l'article 56-bis de la Llei 98/2013. Dels 1.000 béns posats a disposició pel Ministeri de Defensa l'any 2013, solament 333 han estat sol.licitats per les autoritats locals, 239 dels quals van ser declarats transferibles per l'Agència del Domini. Fins al mes de febrer de 2016, només en van ser transferits 39 després de la resolució de la junta dels municipis implicats. Les opinions negatives en van ser 34, mentre que encara se n'estan definint 21 casos. No obstant això, encara no està disponible la distribució dels béns per províncies i regions. En segon lloc, els nous protocols de col-laboració interinstitucionals - Protocolli d'intesa - per a la reutilització del patrimoni militar abandonat tenen la tasca d'accelerar el procés de reconversió, per finalitzar en acords de programes - Accordi di Programma - (Gastaldi i Camerin, 2014). En tercer lloc, l'article 26 «Mesures urgents per a la millora d'edificis públics en desús» contingut a la Llei 164/2014 «Desbloqueja Itàlia», va introduir la possibilitat de celebrar acords de programes per modificar els instruments de planificació per a béns militars, identificats amb un decret ministerial, per desenvolupar projectes de reconversió en habitatge públic. En principi, es van identificar 11 immobles de propietat del Ministeri de Defensa mitjançant el Decret del Ministeri d'Economia i Hisenda de 24 de desembre de 2014. També es van promulgar dos decrets d'identificació més, l'un es va emetre el 30 de juliol de 2015 i feia referència a dos béns militars situats a Bari, i l'altre, el 21 de desembre de 2015 i al-ludia a una antiga caserna de Grosseto. El mes de febrer de 2016, el procediment de l'article 26 del Decret «Desbloqueja Itàlia» es troba encara en les etapes inicials pel que fa a l'avaluació d'alguns projectes de recuperació de béns militars abandonats ubicats a les ciutats capital de província de Novara, Ravenna i Udine. Per rehabilitar l'antic arsenal de Pavia, s'ha promogut un procés de planejament participatiu, mentre que a Bari es van activar dues iniciatives. L'una tractava sobre la racionalització dels espais utilitzats pel Govern mitjançant la ubicació d'una seu de la justícia a la caserna de Milà, mentre que l'antic hospital militar Bonomo hauria de respondre a la falta d'habitatge protegit 


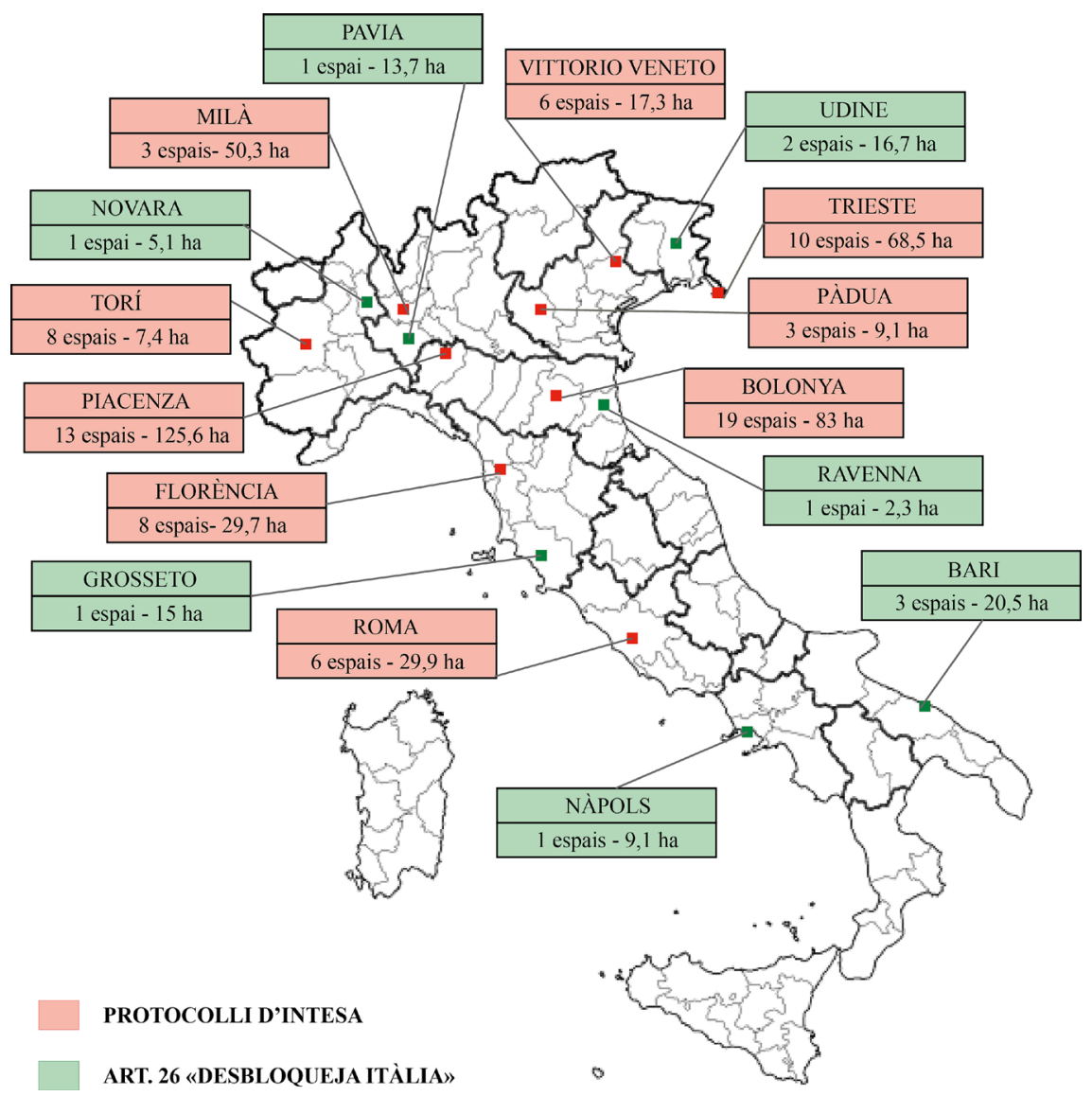

Figura 3. Mapa de localització dels procediments actuals per reconvertir el patrimoni militar italià. S'hi han assenyalat els casos de les ciutats que són capital de província. A més, s'hi ha afegit el cas del protocol que fa referència a les àrees ubicades en el municipi de Vittorio Veneto (prov. Treviso).

Font: elaborat per Federico Camerin (febrer de 2016).

a la ciutat. A causa de la manca d'informació sobre el federalismo demaniale, s'ha desenvolupat un mapa sobre l'article 26 del Decret «Desbloqueja Itàlia» i els Protocolli d'intesa, on es posen en evidència les ciutats capital de província involucrades en els dos processos, amb el nombre d'espais militars i l'àrea total que ocupen. A més, a l'apartat següent, es focalitza l'atenció sobre els Protocolli d'intesa, que inclouen béns militars abandonats ubicats a les ciutats italianes més grans, com ara Milà, Roma, Torí i Florència, i a ciutats amb una forta presència d'àrees militars abandonades, com ara Bolonya (83 hectàrees) i Piacenza (125,6 hectàrees). 


\section{Els nous acords per reconvertir les zones militars abandonades a Itàlia}

A partir d'abril de 2014, la nova ministra de Defensa, Roberta Pinotti, ha creat una força especial en coordinació amb la societat Servizio Difesa SpA i l'Agenzia del Demanio, amb l'objectiu d'accelerar els processos de reutilització dels béns militars en desús. Es tracta de la signatura de nous protocols de collaboració interinstitucionals, també per reprendre acords ja signats només entre el Ministeri de Defensa i els municipis i fomentats per la Llei de Pressupostos de 2009, atès que el procés no es va completar dintre del termini previst. El protocol haurà de seguir un acord — l'anomenat Accordo di Programma- que modificarà directament el $\mathrm{Pla}$ General d'Ordenació Urbana.

Considerant les exigències de reduir el dèficit, equilibrar i sanejar les finances públiques i el desenvolupament de processos de requalificació i regeneració urbanes, a partir de 2014 es van signar importants protocols nous de col.laboració interinstitucional entre el Ministeri de Defensa, l'Agenzia del Demanio i ajuntaments per al desenvolupament urbà d'immobles militars buits. Els més importants són els de les ciutats de Milà, Torí i Roma, del 7 d'agost, mentre que el primer va ser signat el 17 d'abril del mateix any amb l'Ajuntament de Florència per reconvertir set àrees militars abandonades.

D'aquesta manera, cada ajuntament es compromet, en el termini d'un any a partir de la signatura del protocol, a plantejar les destinacions d'ús dels béns, en línia amb les directrius del Pla General d'Ordenació Urbana o aportant una modificació directa al Pla amb l'Accordo di Programma. La validesa del protocol pot variar si, per part de les institucions, es concerta un nou acord que estigui justificat de manera adequada.

Així doncs, entre novembre de 2014 i octubre de 2015, continua el procés per agilitar la reutilització del patrimoni militar abandonat en diferents ciutats italianes. Mentre per a les casernes de Pàdua i Vittorio Veneto (província de Treviso) es pateixen dificultats operatives relacionades amb el desenvolupament urbà, la ciutat de Trieste ha emmarcat deu zones militars buides en els procediments d'aprovació del nou PGOU, el Piano Regolatore Generale Comunale. La reconversió dels béns donarà lloc a funcions noves (comercial, residencial, terciària) i a la realització d'equipaments, amb l'objectiu de recuperar la vitalitat urbana i de reforç del caràcter i de la identitat de l'àmbit ciutadà entès conjuntament.

Pel que respecta a Florència i a Torí, es va signar un document que conclou la primera fase del procés establert amb cadascun dels protocols anteriors. Després d'haver realitzat una anàlisi detallada de cada un dels immobles en termes de les seves característiques històriques i estructurals — en col-laboració amb la Subdirecció General de Protecció del Patrimoni Històric italiana- i sota el perfil urbanístic, s'han indicat les noves destinacions d'ús dels béns. La capital de la Toscana ha identificat una mescla de funcions públiques i privades des de la residència fins als serveis públics, mentre que la ciutat de Piemont s'ha centrat principalment en la construcció d'habitatges socials. 
Piacenza i Bolonya són dues ciutats que van desenvolupar, des de 2007, uns procediments per a la reutilització de les zones militars buides ubicades en els seus territoris a través del programa PUVaT, que s'han actualitzat en els últims mesos. En particular, són dos els documents signats per la ciutat de Piacenza. El primer representa un pas important en la implementació del PUVaT de setembre de 2012 sobre dotze àrees estatals (de les quals sis són militars i ocupen 57,6 ha) perquè el municipi es comprometi a posar en pràctica els escenaris de transformació dins dels instruments urbanístics. De seguida, els béns es col-locaran al mercat immobiliari o s'incorporaran en els plans de racionalització del Govern per reduir la despesa en lloguers. En el marc del segon acord, set edificis militars més (que ocupen prop de $68 \mathrm{ha}$ ) del Ministeri de Defensa s'insereixen en les iniciatives d'alienació finalitzades a l'eliminació del deute públic o en les operacions de racionalització destinades a la limitació de costos estatals. A Bolonya, s'ha firmat un acord preliminar per a la realització de les noves previsions urbanístiques sobre algunes àrees incloses en el PUVaT de 2007, que conté un lot de divuit propietats militars abandonades, incloent-hi un campus universitari, un nou sistema de parcs públics i importants equipaments urbans.

Els Protocolli d'intesa van contribuir a establir una relació directa entre el procés de reconversió i la planificació ordinària, i els diferents ajuntaments estan tractant de desenvolupar els projectes sobre els buits militars a llarg termini juntament amb l'avaluació de sostenibilitat d'algunes solucions bastant complexes. La gran durada de l'actuació en els processos de reutilització mostra clarament que les incerteses a nivell nacional es traslladen en la lenta resposta que el mercat i la societat donen a totes les iniciatives estatals promogudes durant els últims quinze anys, malgrat els esforços per part dels governs locals per inserir aquests canvis en els instruments de planejament urbanístic.

\section{Conclusions}

En el marc de referència sobre l'alienació i la reutilització del patrimoni públic, aquest article contribueix a posar en evidència les inèrcies $i$ les qüestions obertes que caracteritzen el procés de reconversió de les àrees militars abandonades a Itàlia, tal com ho demostren els casos dels Protocolli d'intesa. Malgrat que, en els procediments, s'hagi arribat a realitzar una definició compartida de les orientacions i de les prioritats estratègiques, dels rols dels actors involucrats i de la identificació dels nous usos dels béns, es tracta d'accions que han contribuït només a crear les condicions bàsiques per a la futura transformació dels actius en desús.

Una gestió eficaç i eficient del patrimoni immobiliari de l'Estat italià pot ser implementada de manera virtuosa només si hi ha una gestió atenta dels organismes públics que identifiquin les perspectives reals de transformació i el desenvolupament econòmic dels seus territoris, després d'haver realitzat un examen exhaustiu dels interessos potencials públics i privats, socials i econòmics. Unes decisions transparents i participatives permetrien realitzar una mediació 
respecte als conflictes que normalment es produeixen al voltant dels processos de transformació urbana i del govern del territori. Durant els últims anys, les vicissituds de l'alienació i la reutilització dels edificis públics han demostrat ser un «indicador» de les dificultats del marc normatiu italià per reconciliar els objectius estatals $\mathrm{i}$ les potencialitats locals. Una oportunitat perduda, almenys fins ara. La crisi econòmica ha accentuat les tendències ja existents $\mathrm{i}$ ha destacat encara més la ineficàcia de les institucions en aquest àmbit.

La futura recerca sobre el tema de la reconversió del patrimoni militar en desús a Itàlia s'hauria de desenvolupar cap a l'anàlisi dels procediments actuals (a més dels protocols interinstitucionals, cal prestar atenció a l'actuació del federalismo demaniale i de l'article 26 del Decret "Desbloqueja Itàlia»), cap a les futures actualitzacions de la normativa i cap a la realització d'un cens de les àrees militars en ús i en desús. Tot això ajudaria a entendre més bé la dimensió real de la qüestió, sobretot per impulsar projectes de regeneració urbana en una òptica sostenible. De cara al futur, fins i tot a través de la intermediació de l'Agenzia del Demanio, s'hauria de fomentar el debat públic sobre el tema de les alienacions militars, així com la realització d'activitats participatives en el territori i en el món acadèmic, amb l'objectiu de definir les possibles transformacions de les àrees, fins i tot amb usos temporals.

\section{Referències bibliogràfiques}

Antoniol, Marco (2010). Il federalismo demaniale: Il principio patrimoniale del federalismo fiscale. Pàdua: Exeo Edizioni.

Aycart Luengo, Carmen (2001). «Vías verdes, reutilización de ferrocarriles en desuso para movilidad sostenible, ocio y turismo». Informes de la Construcción, 53 (475), 17-32.

Baccichet, Moreno (2015). Fortezza FVG: Dalla Guerra Fredda alle aree militari dismesse. Monfalcone: Edicom.

BAgAEEN, Samer (2006). «Redeveloping former military sites: Competitiveness, urban sustainability and public participation». Cities, 23 (5), 339-352.

Bertolini, Luca i Spit, Tejo (1998). Cities on rail: The redevelopment of railway station areas. Londres: E \& F Spon.

Bodinier, Bernard; Congost Rosa i Luna, Pablo (ed.) (2009). De la Iglesia al Estado: Las desamortizaciones de bienes eclesiásticos en Francia, España y América Latina. Saragossa: Prensas de la Universidad de Zaragoza.

Bonn International Center for Conversion (BICC) (1997). Study on the Re-use of Former Military Lands. Bonn: Federal Ministry for the Environment, Nature Conservation and Nuclear Energy.

Brebbia, Carlos i Clark, Celia (2012). Defence Sites: Heritage and Future. Portsmouth: WIT Press.

- (2014). Defence Sites II: Heritage and Future. Portsmouth: WIT Press.

Conlin, Michael i BIRD, Goffrey (2014). Railway heritage and tourism: Global perspectives. Bristol: Channel View Publications.

Corte dei Conti (2014). Determinazione e relazione della Sezione del controllo sugli enti sul risultato del controllo eseguito sulla gestione finanziaria dell'Agenzia del Dema- 
nio per l'esercizio 2013 [en línia]. Determinazione, núm. 98, 14 de novembre. $<$ http://www.corteconti.it/export/sites/portalecdc/_documenti/controllo/sez_controllo_enti/2014/delibera_98_2014.pdf>.

Dixon, Tim (2006). «Integrating sustainability into brownfield regeneration: Rhetoric or reality? An analysis of the UK development industry». Journal of Property Research, 23 (3), 237-267.

DoAK, J. (1999). «Planning for the Reuse of Redundant Defence Estate: Disposal Processes, Policy Frameworks and Development Impacts». Planning Practice and Research, 14 (2), 211-224.

European Court of Auditors (2012). Have EU structural measures successfully supported the regeneration of industrial and military brownfield sites? Special report núm. 23.

European Union (2003). A secure Europe in a better world. Brussel-les, 12 de desembre de 2003.

FERBER, Uwe et al. (eds.) (2006). Sustainable brownfield regeneration: CABERNET network report. Nottingham: University of Nottingham.

Gaeta, Luca i Savoldi, Paola (eds.) (2013). Orientamenti per la gestione del patrimonio immobiliare pubblico [en línia]. Nàpols: Società Italiana degli Urbanisti. $<$ http://media.planum.bedita.net/20/08/Gestione_beni_immobili_pubblici_ Societ\%C3\%A0_Italiana_degli_Urbanisti.pdf>.

Gastaldi, Francesco i Camerin, Federico (2014). «Novità per la dismissione e valorizzazione dei beni ex militari negli anni 2012-2014». Urbanistica Informazioni, 256, 67-68.

Harness, Stephen (2014). Winston Churchill Fellowship Trust-Military Base Consolidations US experience: Interim fellowship report July 2014 [en línia]. Londres: Winston Churchill Memorial Trust. <http://harnessplanningcom.blogspot.it/2014/07/ churchill-fellowship-interim-report.html>.

Hercik, Jan et al. (2014). «Military brownfields in the Czech Republic and the potential for their revitalisation, focused on their residential function». Quaestiones Geographicae, 33 (2), 127-138.

Hill, Catherine (2000). «Measuring Success in the Redevelopment of Former Military Bases: Evidence from a Case Study of the Truman Annex in Key West, Florida». Economic Development Quarterly, 14 (3), 265-275.

Holman, Barry (2001). «Military Base Closure: Overview of Economic Recovery, Property Transfer and Environmental Clean up». Washington: United States General Accounting Office.

Istituto BRuno LeONi (IBL) (2011). Uscire dalla crisi: Un'agenda di privatizzazioni. Milà: IBL Policy [en línia]. <http://www.brunoleonimedia.it/public/upload/ IBL-PolicyPaper-04-Privatizzazioni.pdf>.

JauhiaInen, Jussy Sakari (2002). «Defence restructuring and conversion». A: TAIPaLE, Ikka et al. (eds.). War or health: A reader. Londres: ZN Spon, 580-588.

Lo Conte, Giustino (2011). «Federalismo demaniale e regime giuridico dei beni pubblici». La Gazzetta Amministrativa della Repubblica Italiana, 1, 24-28.

MagistÀ, Aurelio (ed.) (2007). Tesoro Italia: Edifici e terreni dello Stato. Roma: La Repubblica.

Marcuse, Peter i Van Kempen, Ronald (eds.) (2000). Globalizing Cities: A New Spatial Order? Londres i Cambridge: Blackwell Publishers.

MatLovič, René et al. (2001). «Transformation of the spatial structure of post-communist towns: The case of Prague, Bratislava, Olomouc and Presov». A: JAżDżEwsKA, 
Iwona (ed.). Miasto postkomunistyczne - przemiany przestrzeni miejskiej. Lodz: UL, 9-21.

Montedoro, Laura (2011). A vision for Milan: Rail yards and the city's transformation. Macerata: Quodlibet.

Nijkamp, Peter et al. (2002). «Success factors for sustainable urban brownfield development: A comparative case study approach to polluted sites». Ecological Economics, 40 (2), 235-252.

Parlato, Salvatore i Vaciago, Giacomo (2002). «I problemi della gestione del patrimonio. La dismissione degli immobili pubblici: La lezione del passato e le novità della legge n. 410, 23 novembre 2001». Quaderni Ricerche per l'Economia e la Finanza, 8, 3-27.

Perić, Ana i Furundžić, Danilo (2013). «Collaboration in the brownfield regeneration process: Legally binding or informal approach?». A: Schrenk, Manfred et al. (eds.). Planning Times: Proceedings Real Corp 2013 (CD-ROM), 181-188.

PonzInI, Davide (2008). "La valorizzazione degli immobili statali come opportunità di sviluppo territoriale». Urbanistica, 136, 87-94.

PonZINI, Davide i VANI, Marco (2012). «Immobili militari e trasformazioni urbane». Territorio, 62, 13-18.

REIMER, Kenneth et al. (1997). Environmental contamination and remediation practices at former and active military bases. Vilnius: NATO Science Series 2 Environmental Security, 48.

Rovelli, Roberto; Fumagalli, Natalia i Senes, Giulio (2004). Ferrovie dismesse e greenways: Il recupero delle linee ferroviarie non utilizzate per la realizzazione di percorsi verdi. Milà: Associazione Italiana Greenways.

RuEdA, Germán (1998). «El modelo mediterráneo de la desamortización en la formación de la propiedad liberal». A: CASmirri, Silvana i SuÁrez Cortina, Manuel (eds.). La Europa del sur en la época liberal: España, Italia y Portugal. Una perspectiva comparada. Santander: Universidad de Cantabria, 37-66.

Servizio Studi del Senato (2009). Disegno di legge A.S. n. 1373 "Misure a tutela dei segni distintivi delle Forze armate e costituzione della Società "Difesa Servizi Spa" " [en línia]. Dossier núm. 100. <http://www.senato.it/service/PDF/PDFServer/ BGT/00736490.pdf>.

Silveira, Luis Espinha da (1991). «Venda de bens nacionais, estructura da propiedade e estructura social na região de Évora na primeira metade do sécolo XIX». Analise Social, 112, 585-612.

Simion-Melinte, Cezar (2012). «Reconversion of military sites into business incubators and business support centers: The European experience». Business Excellence and Management, 2 (2), 79-86.

Thornton, Gareth et al. (2007). "The challenge of sustainability: Incentives for brownfield regeneration in Europe». Environmental Science \& Policy, 10, 116-134.

VACiago, Giacomo (2007). «Gli immobili pubblici... ovvero, purché restino immobili». A: MatTeI, Ugo et al. (coords.). Invertire la rotta: Idee per una riforma della proprietà pubblica. Bolonya: Il Mulino, 325-339.

Van Driesche, Jason i Lane, Marcus (2002). "Conservation through Conversation: Collaborative Planning for Reuse of a Former Military Property in Sauk County, Wisconsin, USA». Planning Theory \& Practice, 3 (2), 133-153.

Villani, Pasquale (1964). La vendita dei beni dello Stato nel Regno de Napoli (18061815). Milà: Banca Comerciale Italiana. 
Vojvodíková, Barbara (ed.) (2010). Brownfields-Handbook: Cross-disciplinary educational tool focused on the issue of brownfields regeneration. Ostrava: VŠB-Technical University of Ostrava.

WARF, B (1997). «The geopolitics/geoeconomics of military base closures in the USA». Political Geography, 16 (7), 541-563.

Wedding, Chistopher i Crawford-Brown, Douglas (2007). «Measuring site-level success in brownfield redevelopments: A focus on sustainability and green building». Journal of Environmental Management, 85 (2), 483-495. 